\title{
Dental Treatment of Two Children with Niemann Pick Disease Type B Under General Anesthesia: Case Reports
}

\author{
(D) Mustafa Sarp KAYA ${ }^{1}$, iD Meltem BAKKAL ${ }^{1}$, iD Serdar YEŞILTAŞ2
}

1Bezmialem Vakıf University Faculty of Dentistry, Department of Pedodontics, İstanbul, Turkey

${ }^{2}$ Bezmialem Vakıf University Faculty of Medicine, Department of Anaesthesiology and Reanimation, İstanbul, Turkey

\begin{abstract}
Niemann-Pick disease (NPD) is an autosomal recessive lysosomal lipid storage disorder with accompanying symptoms including hepatosplenomegaly and thrombocytopenia. Delayed or extensive dental treatment may need to be delivered under general anesthesia and the management of such treatments in these children may require advanced medical support including intensive care (IC). Two children with NPD type B who underwent dental treatment with general anesthesia and their post-operative follow-ups requiring in IC are were presented. Patients with NPD may present with fragile blood clots in extracted tooth socket and should be subjected to strict bleeding control standards; especially the ones that may require further respiratory assistance since oral intubation is an invasive application to the oral surgical site.
\end{abstract}

Keywords: Niemann-Pick disease, general anesthesia, hemostasis

\section{Introduction}

Niemann-Pick disease (NPD) is an autosomal recessive disorder caused by pathogenic mutations in SMPD1 gene. It is characterized by lysosomal acid sphingomyelinase (ASM) deficiency causing accumulation of cholesterol and sphingomyelin in various organs, intercellular space, central nervous system and especially in reticuloendothelial system cells (1). Type A and B exhibit defective ASM activity in $0-1 \%$ and $1-10 \%$ of the healthy individuals, respectively. Patients with type $\mathrm{C}$ cannot metabolize cholesterol and other lipids properly which cause accumulation in tissues (2). Patients with NPD may present with cerebellar ataxia, dysphagia, dysarthria, progressive neurodegeneration, dementia, mental retardation, seizures, impaired motor development, hepatosplenomegaly, thrombocytopenia, interstitial pulmonary disease and cardiac symptoms which are of significance in anesthesia procedures (1). Diagnosis is based on tissue biopsy showing characteristic foamy histiocytes or ASM enzyme analysis in leucocytes (2). Thrombocytopenia secondary to hypersplenism is a significant factor that leads to difficulties in dental management in these patients (3). We, hereby presented two children with NPD type B who underwent dental treatment with general anesthesia (GA) and their post-operative follow-ups in pediatric intensive care unit (PICU).

\section{Case Reports}

\section{Case 1}

A four-year-old boy was referred for dental treatment due to numerous caries by the ear nose throat specialist who was planning adenoidectomy for obstructive sleep apnea and adenoid hypertrophy. Offspring of a consanguineous marriage, the child was diagnosed with NPD type B and had undergone a bone marrow transplant at the age of two. Intraoral exam that was performed with the assistance of father due to child's limited ability to hold the head erect and keep the mouth open revealed chronic odontogenic abscesses and deep dentinal caries. Dental radiographs could not be taken because diagnostically valid images could not be obtained. Restorations and extractions were planned 
under GA in the same session with and before adenoidectomy (Table 1). Pre-operative blood panel was shown in Table 2; consulting hematologist recommended regular hemostatic precautions and observation in PICU. Written parental informed consent was taken before the operation.

In GA procedure, an intravenous midazolam premedication (0.5 $\mathrm{mg} / \mathrm{kg}$ ) was administered 15 minutes before taken to operating room. Non-invasive blood pressure, echocardiogram and peripheral pulse oximetry were used for standard anesthesia monitorization. Intravenous line using 24 gauge catheter was placed and saline infusion was administered. After 5 minutes of stabilization, patient's heart rate, systolic/diastolic arterial pressure and average arterial pressure were recorded as basal vitals. Before the induction, $6 \mathrm{~L} / \mathrm{min} 100 \%$ oxygen insufflation was achieved. Following preoxygenation, $1 \mathrm{mcg} / \mathrm{kg}$ of fentanyl and $3.5 \mathrm{mg} /$ $\mathrm{kg}$ of propofol doses were administered intravenous. Following the disappearance of eyelash reflex patient was ventilated with airway mask breathing unit and $0.5 \mathrm{mg} / \mathrm{kg}$ recuronium bromide was administered. Patient was intubated orally using (spiral) endotracheal tube. For the maintenance of anesthesia, 50\% nitrous oxide/oxygen and sevofluorane (2\%) were used.

Antisepsis of the oral cavity was performed with $0.12 \%$ chlorhexidine swabbing. Ferric sulfate pulpotomy and composite restorations were performed in all second primary molars, maxillary and mandibular canines were also restored with composite. All primary first molars and maxillary incisors were extracted with local anesthesia (articaine and epinephrine) injection (Table 1). Hemostasis was achieved with gauze pressure and suturing was not necessary in these minor wound sites with closed extractions of roots.

Following dental treatment, adenoidectomy was performed using curette and nasopharynx was packed with gauze for three minutes until bleeding was controlled. Excised tissue was sent for biopsy and foamy histiocyte appearance was detected. Operation site was irrigated with sterile saline nasally and orally and hemostasis was observed. At the end of the operation patient was extubated and transferred to PICU as planned preoperatively.

Patient's oxygen saturation declined four hours after the operation and was decided to be reintubated. Oral intubation preparations dislodged the blood clots leading to hemorrhage from anterior extraction site which had to be sutured after hemostatic agent (Gelfoam, Pfizer, USA) was packed into the sockets before the intubation. Patient received intravenous tranexaminic acid (10 $\mathrm{mg} / \mathrm{kg} /$ day) for four days and post-operative bleeding from extraction sites was stopped in 72 hours. Patient was kept intubated for two days, monitored in PICU for further respiratory distress and discharged on day 11 following surgery.

\section{Case 2}

A nine-year-old boy was admitted for dental treatments before bone marrow transplant to eliminate any possible oral infection focus. Offspring of a consanguineous marriage, child was diagnosed with NPD type B. Intraoral exam revealed multiple carious and infected deciduous and permanent teeth (Figure
Table 1. Dental treatments of the cases

\begin{tabular}{|l|l|l|l|}
\hline & \multicolumn{1}{|c|}{ Teeth extractions } & Restorations & $\begin{array}{l}\text { Pulpal } \\
\text { treatments }\end{array}$ \\
\hline Case 1 & $\begin{array}{l}51,52,61,62,64,74,84 \\
\text { Case } 2\end{array}$ & $\begin{array}{l}53,63,73,83 \\
51,52,53,54,55,63,\end{array}$ & $55,65,75,85$ \\
\hline $64,65,74,75$ & $36,46,73,83$ & 16,26 \\
\hline $\begin{array}{l}\text { Teeth were numbered according to } \\
\text { Classification }\end{array}$ & International Dental Federation \\
\hline
\end{tabular}

Table 2. The preoperative blood panels of 2 cases

\begin{tabular}{|c|c|c|c|c|}
\hline & $\begin{array}{l}\text { International } \\
\text { normalizing } \\
\text { ratio }\end{array}$ & $\begin{array}{l}\text { Prothrombin } \\
\text { time (second) }\end{array}$ & $\begin{array}{l}\text { Activity } \\
\text { (\%) }\end{array}$ & $\begin{array}{l}\text { Thrombocyte } \\
\text { count }\left(10^{3}\right. \\
\text { cells } / \mathrm{mL})\end{array}$ \\
\hline Case 1 & 1.53 & 47.5 & 56.7 & 116 \\
\hline Case 2 & 1.66 & 20.9 & 55.8 & 449 \\
\hline
\end{tabular}

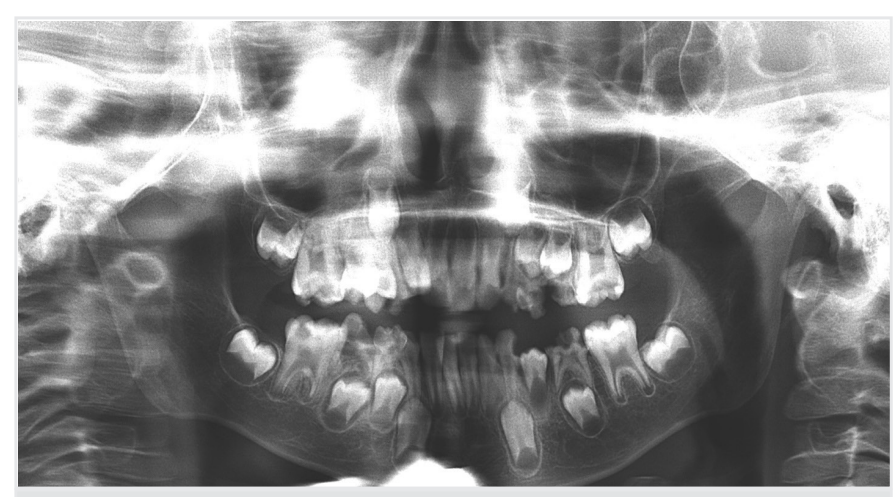

Figure 1. Preoperative radiography of case 2

1). Restorations and extractions were planned under GA due to child's poor rapport (Table 1). Before the dental operation, an anesthesiologist examined the child with pre-operative blood panel that was shown in Table 2. Consulting hematologist suggested regular hemostatic precautions. Written parental informed consent was taken before the operation and the same GA procedure was followed as in case 1 described above. Indirect pulp capping with mineral trioxide aggregate in two maxillary first permanent molars were performed and restored with composite. Two mandibular first permanent molars and both primary canines were restored with composite. Ten primary teeth were extracted after local anesthesia. Hemostasis was achieved with gauze pressure and suturing was not necessary in these minor wound sites with closed extractions of roots. Patient was extubated and referred to PICU for overnight observation and discharged the next day uneventfully.

\section{Discussion}

Children with special health care needs often present high caries risk and high caries activity and oral cavity has frequently been documented as the leading source of sepsis in medically compromised patients $(4,5)$. According to the American Academy of Pediatric Dentistry, GA is indicated in patients with cooperation problems due to physical/medical disability and 
children in need of immediate, comprehensive oral/dental care among others (6). In patients with NPD without severe physical disability and mental retardation, treatment on an outpatient basis may be less costly and encourage the family to be involved in their child's oral health and motivate for follow-ups (2). Although that is not an ideal scenario, unachievable volume of work has been reported as a reason for dental treatment indication under GA (7). Both cases presented were in need of comprehensive dental treatment due to delayed oral care. Since elimination of both the present and possible odontogenic infections was intended in a single-session GA procedure, mostly extractions were preferred. But extractions in these patients may cause unstable blood clots over the course of healing and may cause post-op hemorrhage. Thrombocytopenia may present secondary to hypersplenism in patients with NPD as in case 1 , although this has been reported as clinically insignificant in the literature $(8,9)$. According to the American Academy of Pediatric Dentistry guideline, platelet count below 75000 cells $/ \mathrm{mlis}$ recommended to be checked 24 hours before and after the surgery and hemorrhage control can be provided with application of local hemostatic agents, pressure packs (10). Our patient was above this level and local bleeding control and hemostasis were provided with gauze pressure as suggested by consulting hematologist. But respiratory distress requiring intervention to the oral wound site disorganized blood clots and necessitated impromptu hemostatic control need.

Comprehensive dental treatment under GA in patients with NPD may carry risks due to unforeseeable complications. Dental caries may be prevented or treated earlier by referral to the dental team by their primary physicians as part of their medical management plan. This approach may avoid unnecessary advanced procedures or prevent delay to critical treatments.

Patients with NPD may present with unstable blood clots and should be subjected to strict bleeding control standards; especially the ones that may require further respiratory assistance since oral intubation is an invasive application to the oral surgical site.

\section{Ethics}

Informed Consent: Written informed consent was obtained from the patients who participated in this study.

Peer-review: Internally peer-reviewed.

\section{Authorship Contributions}

Surgical and Medical Practices: M.S.K., M.B., Concept: M.S.K., Design: M.S.K., Data Collection or Processing: M.S.K., M.B.,
Analysis or Interpretation: M.S.K., M.B., S.Y., Literature Search: M.S.K., M.B., Writing: M.S.K., M.B.

Conflict of Interest: No conflict of interest was declared by the authors.

Financial Disclosure: The authors declared that this study received no financial support.

\section{References}

1. Zorlu P, Ucar Ş, Yarali N, Demirceken F. Niemann-Pick hastaligi tip A ve tip B: Iki olgu sunumu. Marmara Medical Journal 2014;27:547.

2. Kaisare S. Gingival enlargement in Niemann-Pick disease: a coincidence or link? Report of a unique case. Oral Surg Oral Med Oral Pathol Oral Radiol Endod 2007;104:35-9.

3. Wasserstein MP, Desnick RJ, Schuchman EH, Hossain S, Wallenstein S, Lamm C, McGovern MM. The natural history of type B NiemannPick disease: results from a 10-year longitudinal study. Pediatrics 2004;114:672-7.

4. American Academy of Pediatric Dentistry. Guideline on dental management of pediatric patients receiving chemotherapy, hematopoietic cell transplantation, and/or radiation. Pediatr Dent 2013;35:298-306.

5. Mesquita-Guimarães KS, De Rossi A, Freitas AC, Nelson-Filho P, da Silva RA, de Queiroz AM. Changes in caries risk and activity of a 9-year-old patient with niemann-pick disease type C. Case Rep Dent 2015;2015:571098.

6. American Academy of Pediatric Dentistry. Guideline on behavior guidance for the pediatric dental patient. Pediatr Dent 2008;30:12533.

7. Dougherty N. The dental patient with special needs: a review of indications for treatment under general anesthesia. Spec Care Dentist 2009;29:17-20.

8. Fillmore WJ, Leavitt BD, Arce K. Dental extraction in the thrombocytopenic patient is safe and complications are easily managed. J Oral Maxillofac Surg 2013;71:1647-52.

9. Henderson JM, Bergman S, Salama A, Koterwas G. Management of the oral and maxillofacial surgery patient with thrombocytopenia. J Oral Maxillofac Surg 2001;59:421-7.

10. American Academy of Pediatric Dentistry. Guideline on management of dental patients with special health care needs. Pediatr Dent 2012;34:166-71. 